\title{
Serum Apolipoprotein-A1 and Cholesterol Levels in Nigerian Children with Plasmodium falciparum Infection
}

\author{
Adebola Emmanuel Orimadegun ${ }^{a}$ Bose Etaniamhe Orimadegun ${ }^{b}$ \\ ${ }^{a}$ Institute of Child Health and ${ }^{b}$ Department of Chemical Pathology, College of Medicine, University of Ibadan, \\ Ibadan, Nigeria
}

\section{Key Words}

Apolipoprotein-A1 P Plasmodium falciparum · Malaria . Lipids

\begin{abstract}
Objective: This study was carried out to determine whether or not Plasmodium falciparum malaria infection significantly affected apolipoprotein-A1 and cholesterol levels and if apolipoprotein-A1 correlated with the malaria severity in children younger than 5 years old. Subjects and Methods: Two hundred and fifty-five children, 170 of whom had microscopically confirmed $P$. falciparum infection, i.e. 85 cases of uncomplicated malaria (UM) and 85 of complicated malaria (CM), and 85 healthy controls were enrolled in this study. Serum levels of apolipoprotein-A1, total cholesterol, highdensity lipoprotein (HDL), low-density lipoprotein (LDL) and triglycerides were determined. These levels were compared among the malaria and control groups, using ANOVA and post hoc analyses at $p=0.05$. Results: There were significant differences in the mean serum levels of apolipoprotein-A1 (UM: $104.5 \pm 38.1 \mathrm{mg} / \mathrm{dl}, \mathrm{CM}: 90.9 \pm 33.3 \mathrm{mg} / \mathrm{dl}$ and controls: $129.7 \pm 48.3 \mathrm{mg} / \mathrm{dl} ; \mathrm{p}<0.001)$, total cholesterol (UM: $138.8 \pm$ $62.9 \mathrm{mg} / \mathrm{dl}, \mathrm{CM}: 121.2 \pm 55.2 \mathrm{mg} / \mathrm{dl}$ and controls: $155.1 \pm 69.8$ $\mathrm{mg} / \mathrm{dl} ; \mathrm{p}=0.002)$ and LDL (UM: $98.2 \pm 55.5 \mathrm{mg} / \mathrm{dl}, \mathrm{CM}: 84.3$ $\pm 47.4 \mathrm{mg} / \mathrm{dl}$ and controls: $122.7 \pm 69.4 \mathrm{mg} / \mathrm{dl} ; \mathrm{p}<0.001$ ).
\end{abstract}

Post hoc analyses revealed that children with UM and CM had significantly lower levels of apolipoprotein-A1, cholesterol, HDL and LDL than controls but that there was no difference between the 2 malaria groups. Reductions in levels of lipids and apolipoprotein-A1 were worse in CM than in UM. Conclusion: Altered levels of serum lipids with CM were associated with a reduction in apolipoprotein-A1. These findings have potential diagnostic utility for the management of malaria.

(c) 2015 S. Karger AG, Basel

\section{Introduction}

Malaria remains a global health problem and a threat to the life of about $40 \%$ of the world population in spite of efforts at prevention and improvements in treatment [1]. Malaria accounts for an estimated $18 \%$ of deaths among children younger than 5 years of age worldwide, and $>90 \%$ of these deaths occur in sub-Saharan Africa [1]. Though the burden of morbidity due to malaria has declined in many countries, the disease and its complications still account for about $30 \%$ of childhood mortality, $11 \%$ of maternal mortality and $30-40 \%$ of out-patient clinic consultations in Nigeria [2].

\begin{tabular}{ll}
\hline KARGER 125:s & $\begin{array}{l}\text { () 2015 S. Karger AG, Basel } \\
1011-7571 / 15 / 0244-0318 \$ 39.50 / 0 \quad \text { Karger }\end{array}$ \\
$\begin{array}{l}\text { E-Mail karger@karger.com } \\
\text { www.karger.com/mpp }\end{array}$ & $\begin{array}{l}\text { This is an Open Access article licensed under the terms of the } \\
\text { Creative Commons Attribution-NonCommercial 3.0 Un- } \\
\text { ported license (CC BY-NC) (www.karger.com/OA-license), } \\
\text { applicable to the online version of the article only. Distribu- } \\
\text { tion permitted for non-commercial purposes only. }\end{array}$
\end{tabular}

Adebola E. Orimadegun

Institute of Child Health, College of Medicine

University of Ibadan

Ibadan (Nigeria)

E-Mail beorimadegun@yahoo.com 
Children younger than 5 years are particularly vulnerable to malaria infections and its attendant complications, which can be almost wholly attributed to Plasmodium falciparum infection in the sub-Saharan African population [3]. Visser et al. [4] reported on potential biochemical molecules that may be targeted for diagnostic and therapeutic procedures, for example, $P$. falciparum, which thrives by interacting with host molecules like protein and lipids.

Some clinical studies show that the lipid profile of patients with malaria infection changes considerably, to the extent that this could be attributed wholly to the parasitaemia $[5,6]$. While some studies report no correlation between the severity of malaria and the extent of lipid profile changes $[7,8]$, in others, the magnitude of observed changes has been related to the severity of malaria $[9,10]$. So far, the existing literature suggests that changes in the lipid profile during malaria illness are transient and occur in the acute phase. Thus, it has been suggested that lipids as well as sub-classes and related metabolites constitute potential adjuvant diagnostic tools for malaria as well as targets for treatment $[7,11,12]$.

Apolipoproteins and the sub-class apolipoprotein-A1 are proteins that bind to lipids to form lipoproteins. Their main function is to transport lipids; they play an important role in lipoprotein receptor recognition as well as the regulation of certain enzymes in lipoprotein metabolism [13]. While many studies have reported low lipid levels in patients with malaria [13-15], data in the literature on an inter-relationship between apolipoprotein-A1, cholesterol and P. falciparum infection are scarce [15-18]. No meta-analysis has been conducted on the actual effect that malaria has on apolipoprotein because of insufficient data. Notably, a cross-sectional study showed that significantly lowered apolipoprotein-A1 levels occurred in a malaria group but not in healthy individuals [17]. Conversely, Cuisinier-Raynal et al. [18] reported no significant difference in the apolipoprotein-A1 levels of 144 non-immune adults who stayed in Central Africa for 4 months compared to controls. More recently, Simpson et al. [19] demonstrated a lower level of apolipoprotein-A1 in severely anaemic, malaria-exposed primigravidae compared with multigravid pregnant women. Ray et al. [20] suggested the potential discriminatory ability of apolipoprotein-A1 for malaria infection among adults [21]. However, a number of characteristics (the differences between pregnant women/adults and children younger than 5 years) underscore the need to examine the possible peculiarities of lipid metabolism, especially apolipoprotein-A1, in children with malaria.

Levels of Serum Apolipoprotein-A1 and Cholesterol in Malaria
In Nigeria, two studies $[22,23]$ found in public domain investigated the influence of malaria infection on cholesterol. The reports of these studies are limited because of the methodology and the number of participants, and neither study assessed the level of apolipoprotein-A1. For instance, Agbedana et al. [23] reported significantly lower levels of serum high-density lipoprotein (HDL) among 15 patients with malaria compared to 15 controls over 24 years ago, but apolipoprotein-A1, a major protein component of HDL, was not measured. More recently, Chukwuocha and Eke [22] investigated the relationship between malaria parasite status and cholesterol level in 110 adults; again, apolipoprotein-A1 was not measured. It is important to note that children were not included in their study and absolute parasite counts were not performed; this makes it difficult to objectively assess the effects of malaria severity on lipids. Thus far, the available literature suggests that children with malaria may exhibit remarkable lipid derangement, but litthe is known about the serum apolipoprotein-A1 profile during malaria illness. Therefore, this study was carried out to find out whether malaria infection significantly affects apolipoprotein-A1 as well as other lipids in Nigerian children.

\section{Material and Methods}

\section{Study Design and Setting}

In this case control study, data from 255 children were analyzed and presented. There were 170 cases with microscopically confirmed $P$. falciparum malaria infection, i.e. 85 complicated malaria (CM) and 85 uncomplicated malaria (UM) cases. The controls were 85 healthy children with a negative blood smear for malaria parasites. The cases were age-matched to the controls. The children were grouped according to age: 6-11, 12-23, 24-35, 3647 and 48-59 months. Cases were recruited from the Children's Clinics and Emergency Unit of the University College Hospital (UCH), Ibadan, Nigeria, from April 2011 to March 2013, while controls were selected from among children living in the same neighbourhood as the respective cases. The UCH is foremost a tertiary referral hospital located in Ibadan, south-west Nigeria. There are approximately 2,500 admissions yearly to the UCH Department of Paediatrics, and about $11 \%$ of these are CM cases. Based on the 2006 national census, Ibadan has an estimated population of $2,550,393$.

\section{Study Population and Sampling}

Ethical approval for the study was obtained from the University of Ibadan/UCH Ibadan Ethics Review Committee. Participation in the study was completely voluntary and based on written informed consent obtained from parents or caregivers, who were made to understand that they were free to refuse consent and that due treatment would not be denied (according to the treatment guideline). 
Table 1. Demographic characteristics, weight and parasite counts of children with malaria and controls

\begin{tabular}{|c|c|c|c|c|}
\hline & $\begin{array}{l}\text { Control } \\
(\mathrm{n}=85)\end{array}$ & $\begin{array}{l}\text { UM } \\
(\mathrm{n}=85)\end{array}$ & $\begin{array}{l}\text { CM } \\
(n=85)\end{array}$ & $\begin{array}{l}\text { Total } \\
(\mathrm{n}=255)\end{array}$ \\
\hline \multicolumn{5}{|l|}{ Sex, n (\%) } \\
\hline Male & $49(57.6)$ & $48(56.5)$ & $59(56.1)$ & $156(61.2)$ \\
\hline Female & $36(42.4)$ & $37(43.5)$ & $26(30.6)$ & $99(38.8)$ \\
\hline \multicolumn{5}{|l|}{ Age, months } \\
\hline Range & $6.0-59.0$ & $6.0-56.0$ & $9.0-59.0$ & $6.0-59.0$ \\
\hline Median & 34.0 & 32.0 & 37.0 & 35.0 \\
\hline Mean \pm SD & $36.2 \pm 10.9$ & $36.3 \pm 11.5$ & $32.5 \pm 12.3$ & $34.4 \pm 11.4$ \\
\hline \multicolumn{5}{|l|}{ Weight, kg } \\
\hline Range & $6.5-16.0$ & $5.9-15.7$ & $8.5-14.5$ & $5.9-16.0$ \\
\hline Median & 11.0 & 10.0 & 11.5 & 11.5 \\
\hline Mean \pm SD & $12.2 \pm 3.2$ & $13.4 \pm 4.6$ & $14.2 \pm 2.3$ & $13.6 \pm 4.1$ \\
\hline \multicolumn{5}{|l|}{ MP counts (per ml) } \\
\hline Min.-max. & n.a. & $446-52,079$ & $1,188-25,7426$ & n.a. \\
\hline Median & n.a. & 2,376 & 58317 & n.a. \\
\hline Geometric mean & n.a. & 2,259 & 39,041 & n.a. \\
\hline
\end{tabular}

All the children were enrolled into the study consecutively, using a non-probability convenient-sampling technique. Children who presented with symptoms and signs suggestive of malaria and a confirmed positive blood smear for malaria parasites were considered as cases. Controls were children of similar socioeconomic status who did not have symptoms of malaria and had a negative blood smear for the malaria parasite. All the children with microscopically confirmed $P$. falciparum malaria infection were febrile (axillary temperature $>37.5^{\circ} \mathrm{C}$ ). Cases were grouped into UM and $\mathrm{CM}$ as defined by the World Health Organization [3]. All participants were screened for haemoglobinopathy and those with haemoglobin types SS and SC were excluded from the study.

\section{Sample Size Calculation}

Before the study, we hypothesised that the lowest mean cholesterol levels would be $130.3 \pm 25.2$ and $115.9 \pm 28.7 \mathrm{mg} / \mathrm{dl}$ for healthy controls and cases, respectively. These projections were made from values reported by Agbedana et al. [23]. Using the menu in Stata/SE 12.1 statistical software (StataCorp, College Station, Tex., USA) for estimating sample size for 2-sample comparison at a $95 \%$ level of confidence, $90 \%$ power and a case-to-control ratio of $2: 1$, the estimated minimum required sample size for malaria patients was 148 and 74 for controls.

\section{Data Collection}

A pre-tested, structured, interviewer-administered questionnaire was used to obtain information from parents/caregivers at the time of recruitment by a trained research assistant. Weight and height were also recorded. Each child was examined by the consultant paediatrician (A.E.O.). Laboratory investigations included a blood smear for malaria parasite counts, haematocrit determination and haemoglobin typing. About $3 \mathrm{ml}$ of blood was collected from each subject and the plasma samples were stored at $-20^{\circ} \mathrm{C}$ until a lipid profile was performed. The malaria parasites were counted against 200 white blood cells, and parasite density was calculated for each patient based on an assumed total white blood cell count of $8,000 / \mu \mathrm{l}$ of blood [24]. All children with malaria received standard treatment according to the national guidelines for the treatment of malaria.

\section{Determination of Lipid Profile}

Plasma total cholesterol, HDL and triglyceride levels were determined by an enzymatic colorimetric method using appropriate test kits (Vital Diagnostics SPb Ltd. Petersburg, Russia). The Friedewald formula [25] was used to calculate the low-density lipoprotein (LDL) cholesterol concentration except in participants with serum triglyceride levels $>309 \mathrm{mg} / \mathrm{dl}(<8.0 \mathrm{mmol} / \mathrm{l})$. Apolipoprotein-A1 levels were determined by turbidimetric measurement using test kits (DIALAB Production GmbH, Wiener Neudorf, Austria).

\section{Statistical Analyses}

Data were analyzed using the Statistical Package for Social Scientists (SPSS) 17.0 for Windows (SPSS Inc., Chicago, Ill., USA). All continuous variables were checked for normality using the Shapiro-Wilks test to identify those that were non-parametric in distribution. Analysis of variance (ANOVA) or its non-parametric equivalent, the Kruskal-Wallis $\mathrm{H}$ test, was used to compare the mean values of the 3 groups, i.e. the UM, CM and control groups. Post hoc, pair-wise comparisons with Bonferroni's adjustments were also done to detect differences between 2 groups. Spearman's rho correlation analysis was used to assess correlations between parasite counts and plasma levels of lipids. $\mathrm{p}<0.05$ was considered statistically significant. Receiver operating characteristic (ROC) curve analysis was carried out to evaluate the individual performance of cholesterol and apolipoprotein-A1 levels for predicting $\mathrm{CM}$, and the resulting curves are displayed. 
Table 2. Comparisons of lipid levels for the 2 groups with malaria and the control group

\begin{tabular}{|c|c|c|c|c|c|}
\hline Lipid levels, mg/dl & $\begin{array}{l}\text { Control } \\
(\mathrm{n}=85)\end{array}$ & $\begin{array}{l}\text { UM } \\
(\mathrm{n}=85)\end{array}$ & $\begin{array}{l}\text { CM } \\
(\mathrm{n}=85)\end{array}$ & F-statistic & $\mathrm{p}$ value \\
\hline Total cholesterol & $155.1 \pm 69.8$ & $138.8 \pm 62.9$ & $121.2 \pm 55.2$ & 6.16 & 0.002 \\
\hline LDL & $122.7 \pm 69.4$ & $98.2 \pm 55.5$ & $84.3 \pm 47.4$ & 9.55 & $<0.001$ \\
\hline HDL & $10.0 \pm 8.8$ & $7.9 \pm 6.8$ & $7.2 \pm 6.4$ & 3.29 & 0.039 \\
\hline Triglycerides & $111.7 \pm 55.1$ & $102.1 \pm 49.3$ & $100.8 \pm 48.4$ & 1.14 & 0.322 \\
\hline
\end{tabular}

Table 3. Pair-wise comparisons of lipid levels for malarial patients and the control group

\begin{tabular}{lllr}
\hline Lipid levels, mg/dl & $\begin{array}{l}\text { Mean } \\
\text { difference }\end{array}$ & 95\% CI & \\
\hline Total cholesterol & & & \\
$\quad$ UM vs. controls & 16.4 & -39.6 to 6.9 & 0.274 \\
CM vs. controls & 33.9 & -57.1 to -10.6 & 0.002 \\
CM vs. UM & 17.5 & -40.7 to 5.7 & 0.212 \\
LDL & & & \\
UM vs. controls & 24.6 & -46.0 to -3.1 & 0.019 \\
CM vs. controls & 38.5 & -59.9 to -17.0 & $<0.001$ \\
CM vs. UM & 13.9 & -35.4 to 7.6 & 0.359 \\
HDL & & & \\
UM vs. controls & 2.1 & -4.8 to 0.7 & 0.205 \\
CM vs. controls & 2.8 & -5.5 to -0.1 & 0.043 \\
CM vs. UM & 0.7 & -3.5 to 2.0 & 1.000 \\
Triglycerides & & & \\
UM vs. controls & 9.5 & -28.4 to 9.3 & 0.673 \\
CM vs. controls & 10.8 & -29.6 to 8.1 & 0.507 \\
CM vs. UM & 1.3 & -20.1 to 17.6 & 0.898 \\
Apolipoprotein-A1 & & & \\
UM vs. controls & 25.3 & -23.9 to -10.3 & $<0.001$ \\
CM vs. controls & 38.8 & -53.8 to -23.9 & $<0.001$ \\
CM vs. UM & 13.6 & -28.5 to 1.4 & 0.089 \\
\hline
\end{tabular}

\section{Results}

Demographics, Clinical Data and Parasite Counts

Demographic characteristics, weight and parasite counts of the children with malaria and the controls are shown in table 1. In all, there were more male than female children (males:females $=1.6: 1$ ). The mean age of children with CM (32.5 \pm 12.3 months), UM (36.3 \pm 11.5 months) and controls (36.2 \pm 10.9 months) was not significantly different $(\mathrm{F}=2.972$, d.f. $=2,252$; $\mathrm{p}=0.053)$. Although age is an important determinant of malaria morbidity, there was no statistical difference in the distribution of UM, CM and control groups with respect to age.
Table 4. Correlations of parasite counts and plasma lipid levels in malaria patients by means of Spearman rho correlation analysis

\begin{tabular}{lrrrrr}
\hline & \multicolumn{2}{c}{ UM } & & \multicolumn{2}{c}{$\mathrm{CM}$} \\
\cline { 2 - 3 } \cline { 5 - 6 } & $\mathrm{r}$ & $\mathrm{p}$ & & $\mathrm{r}$ & $\mathrm{p}$ \\
\hline Total cholesterol & -0.019 & 0.865 & & -0.209 & 0.055 \\
LDL & 0.053 & 0.633 & & 0.134 & 0.221 \\
HDL & -0.008 & 0.944 & & -0.012 & 0.914 \\
Triglycerides & 0.022 & 0.839 & & -0.104 & 0.342 \\
Apolipoprotein-A1 & -0.413 & 0.003 & & -0.532 & $<0.001$ \\
\hline
\end{tabular}

There was also no significant difference in the mean weight (in kilograms) of all 3 groups. However, the parasite count (per microlitre) of the children in the CM group (median 58,317 and range 1,188-257,426) was significantly higher than in the UM group (median 2,376 and range 446-52,079).

Of the 85 children in the CM group, 28 (32.9\%) presented with severe anaemia (haemoglobin $<5 \mathrm{~g} / \mathrm{dl}$ ), 19 (22.4\%) had an altered level of consciousness, 17 (20.0\%) had a history of passing dark urine plus positive urine dipstick test results for blood, $9(10.6 \%)$ had respiratory distress plus acidosis, 8 (9.40\%) had multiple convulsions and 7 had $(8.2 \%)$ prostration. Two children presented with oliguria (i.e. a urine output $<1.0 \mathrm{ml} / \mathrm{m}^{2} / \mathrm{h}$ ) which resolved within $48 \mathrm{~h}$ of admission following the administration of intravenous fluid. All of the 28 children with severe anaemia were transfused with packed red blood cells at $10-15 \mathrm{ml} / \mathrm{kg}$ of body weight. None of the study patients had any established signs of shock and no deaths occurred.

\section{Lipid Profile of the Study Participants}

The mean values of the serum lipids for the 3 groups are shown in table 2. All plasma lipids except for triglycerides were significantly lower in the malaria groups (UM and CM) than in the controls. Post hoc analyses 


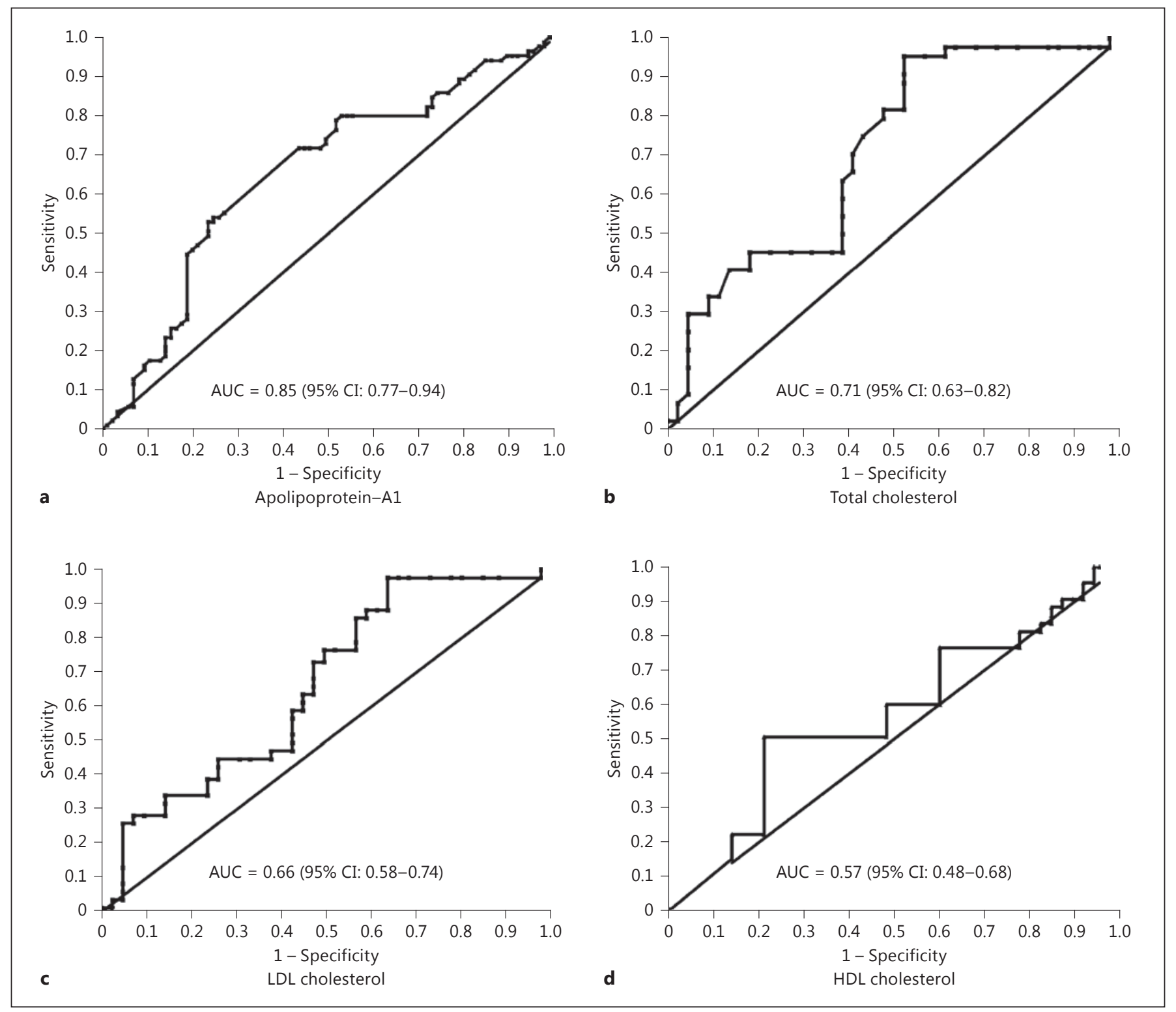

Fig. 1. Discrimination of CM from UM from analysis of the apolipoprotein-A1 and cholesterol levels. The AUC signifies the accuracy of the apolipoprotein-A1 and cholesterol levels for distin-

guishing CM from UM. An AUC value close to 1 indicates an excellent prediction of the disease. The reference (diagonal) line denotes an uninformative test, with an AUC of 0.50 .

(table 3) revealed that in the CM group, total cholesterol was significantly lower by $33.9 \mathrm{mg} / \mathrm{dl}$ [ $95 \%$ confidence interval (CI) -57.1 to $-10.6, \mathrm{p}=0.002$ ], LDL by $38.5 \mathrm{mg} /$ $\mathrm{dl}(95 \% \mathrm{CI}-59.9$ to $-17.0, \mathrm{p}<0.001)$, HDL by $2.1 \mathrm{mg} / \mathrm{dl}$ and apolipoprotein-A1 by $38.8 \mathrm{mg} / \mathrm{dl}$ ( $95 \% \mathrm{CI}-53.8$ to $-23.9, \mathrm{p}<0.001)$ compared with the control group. However, comparing the UM group with the controls, significantly lower values were recorded only for LDL (mean difference $=24.6 \mathrm{mg} / \mathrm{dl}, 95 \% \mathrm{CI}-46.0$ to $-3.1, \mathrm{p}=$

0.019 ) and apolipoprotein-A1 (mean difference $=25.3$ $\mathrm{mg} / \mathrm{dl}, 95 \% \mathrm{CI}-23.9$ to $-10.3, \mathrm{p}<0.001$ ). Notably, the mean levels of plasma triglycerides were not significantly different among any of the pair-wise comparisons. The Spearman rho correlations of levels of malaria parasitaemia and plasma lipids are shown in table 4. Only apolipoprotein-A1 levels were low and significantly inversely correlated with the malaria parasite counts in both the UM and CM groups. 
Accuracy of the Lipids and Apolipoprotein-A1 for

Differentiating CM from UM

The area under the ROC curve (AUC) indicates the accuracy of different cholesterols and apolipoprotein-A1 to distinguish CM from UM. The ROC curves demonstrated apolipoprotein-A1 (AUC $=0.85 ; \mathrm{p}<0.001$; fig. 1a), total cholesterol (AUC $=0.71 ; \mathrm{p}<0.001$; fig. $1 \mathrm{~b})$ and LDL cholesterol (AUC $=0.66 ; \mathrm{p}<0.001$; fig. 1c) to be good predictors of complicated $P$. falciparum malaria, while the predictive value of HDL cholesterol $(\mathrm{AUC}=0.57 ; \mathrm{p}=$ 0.107; fig. 1d) was not statistically significant. For apolipoprotein-A1, a cut-off value of $94.6 \mathrm{mg} / \mathrm{dl}$ had a specificity and sensitivity of 92.0 and $85.0 \%$, respectively. Total cholesterol exhibited a moderate sensitivity $(68.0 \%)$ and specificity $(87.0 \%)$ for CM at a cut-off value of $87.5 \mathrm{mg} /$ dl while LDL cholesterol, at a cut-off value of $5.3 \mathrm{mg} / \mathrm{dl}$, provided $55.0 \%$ specificity and $52.0 \%$ sensitivity in predicting CM.

\section{Discussion}

The major finding of this study was that the level of apolipoprotein-A1 was remarkably lower in malaria patients than in healthy children and the serum level was inversely correlated with the degree of parasitaemia. This is consistent with the findings of previous studies [1518]. The magnitude of the differences in the level apolipoprotein-A1 levels was also greater in the CM group than in the UM group. The effect of malaria on lipids and apolipoprotein-A1 is expected to become more pronounced as age increases [4], but this trend was not demonstrated by our data and the reason for this is unclear. However, our data suggest that the observed lower serum lipid profile in malaria patients (vs. controls) could be specific for $P$. falciparum malaria infection. Specifically, the findings of lower total cholesterol, HDL and LDL in the children with malaria compared with healthy controls corroborated earlier reports [15-18, 22, 23]. One important fact that lends credence to this characteristic feature is that the decline in lipid profile observed among children with malaria appears to be significantly more pronounced than previously observed in any infection [26].

One plausible explanation for malaria patients having lower lipid levels than healthy children is the impairment of lipid synthesis and the excessive consumption of lipids by the parasites [27]. Lipids are synthesized in the liver, through which infective malaria sporozoites pass in order to enter the bloodstream. The parasite invades and resides in the liver cells [28]. In this exoerythrocytic stage, the malaria parasites divide until many mature tissue schizonts are formed. Thereafter, the merozoites are released from the liver into the bloodstream, initiating the erythrocytic stage. Within the erythrocyte, a single merozoite divides into several merozoites [28]. All these developments and cell divisions demand substantial amounts of proteins and lipids, such as cholesterol and lipoproteins, for processes like membrane formation. However, it is not clear from the literature 'what relationships exist between malaria parasites and lipid synthesis in the liver?' and 'whether or not malaria parasites are capable of producing essential lipids themselves or do they utilise the host lipids?' Another important question that remains unanswered is 'whether or not malaria parasites benefit from low serum lipids in the host environment?'

The ROC analyses of the serum levels of cholesterol and apolipoprotein-A1 differentiated the predictions for CM from those for UM, indicating that these levels are indeed potential surrogate markers for distinguishing CM from UM. Though our data showed that reduced serum lipids and apolipoprotein-A1 were characteristic of acute falciparum malaria, other factors may also be responsible for lowering these levels. Further research into the biological mechanisms may explain these aberrations and provide new knowledge on the role of lipids in the pathogenesis of malaria. Research will also present opportunities to explore the utility of apolipoprotein-A1 in the search for interventions for malaria. Nonetheless, the already-documented low levels of apolipoprotein-A1 that accompany P. falciparum infection are of significant potential value in the clinical diagnosis of malaria and the monitoring of recovery from malaria illness.

Our study has some limitations. First, the time that the reduced serum lipid profile took to recover among the malaria patients was not investigated. In some previous studies [4], the reduced lipid level was reported to have returned to normal slowly; in only one study was the level of cholesterol significantly lower in the malaria patients than in the control group a month after treatment. Past studies did not report the time to recover from the reduced serum apolipoprotein-A1. Second, we did not determine the effect that drugs like anti-malarials and adjunct therapy possibly have on lipids. It is thus difficult to completely rule out lipid-lowering effects of such drugs as a reason for the lower levels observed in this study. 


\section{Conclusion}

In this study, reduced levels of serum lipids and apolipoprotein-A1 were characteristic of UM and CM in children younger than 5 years old.

\section{Acknowledgments}

We would like to thank Mr. Nath Afolabi for assisting with the microscopy and haemoglobin typing, Mr. Emmanuel Oni, the research assistant on the project, all the resident doctors who worked in the Emergency Ward during the study period and all nursing staff of the Children Emergency Unit of the University College Hospital, Ibadan for their assistance. This research was partly funded from Hitachi Medical Systems Research Seed Grant 2010.

\section{Disclosure Statement}

There are no disclosures.

\section{References}

1 WHO: World malaria report 2013. WHO $>_{11}$ Nilsson-Ehle I, Nilsson-Ehle P: Changes in Global Malaria Programme. http://www.who. int/malaria/publications/world_malaria_report_2013/en/.

2 Federal Ministry of Health: National guidelines for diagnosis and treatment of malaria, 2011. http://www.nmcp.gov.ng/Table/sitecontent/.

3 WHO: Severe falciparum malaria. WHO Communicable Diseases Cluster. Trans R Soc Trop Med Hyg 2000;94(suppl 1):S1-S90.

4 Visser BJ, Wieten RW, Nagel IM, et al: Serum lipids and lipoproteins in malaria - a systematic review and meta-analysis. Malar J 2013; 12:442.

5 Chagnon A, Guiguen Y, Sutre E: Hypocholesterolemia in malaria: an aid to diagnosis? Semaine des Hopitaux 1985;61:2075-2076.

-6 Faucher JF, Ngou-Milama E, Missinou MA, et al: The impact of malaria on common lipid parameters. Parasitol Res 2002;88:10401043.

7 Kittl EM, Diridl G, Lenhart V, et al: HDL cholesterol as a sensitive diagnostic parameter in malaria. Wien Klin Wochenschr 1992;104: 21-24.

8 Baptista JL, Vervoort T, van der Stuyft P, et al Changes in plasma lipid levels as a function of Plasmodium falciparum infection in Sao Tome. Parasite 1996;3:335-340.

-9 Davis TM, Sturm M, Zhang YR, et al: Plateletactivating factor and lipid metabolism in acute malaria. J Infect 1993;26:279-285.

10 Mohanty S, Mishra SK, Das BS, et al: Altered plasma lipid pattern in falciparum malaria. Ann Trop Med Parasitol 1992;86:601-606. plasma lipoproteins in acute malaria. I Intern Med 1990;227:151-155.

12 Badiaga S, Barrau K, Parola P, et al: Contribution of nonspecific laboratory test to the diagnosis of malaria in febrile travelers returning from endemic areas: value of hypocholesterolemia. J Travel Med 2002;9:117-121.

13 Rifai N: Lipoproteins and apolipoproteins, composition, metabolism and associated with coronary heart disease. Arch Pathol Lab Med 2000;110:694-704.

14 Mfonkeu JB, Gouado I, Kuate HF, et al: Biochemical markers of nutritional status and childhood malaria severity in Cameroon. Br J Nutr 2010;104:886-892.

15 Djoumessi S: Serum lipids and lipoproteins during malaria infection. Pathol Biol (Paris) 1989;37:909-911.

16 Grobusch MP, Krull M, Teichmann D, et al: Falciparum malaria and Tangier disease. Int $\mathrm{J}$ Infect Dis 2003;7:74-75.

17 Blair S, Carmona J, Correa A: Malaria in children: links between nutrition and immunity. Rev Panam Salud Publica 2002;11:5-14.

$\checkmark 18$ Cuisinier-Raynal JC, Bire F, Clerc M, et al: Human malaria: dysglobulinemia-hypocholesterolemia syndrome. Med Trop (Mars) 1990;50:91-95.

19 Simpson DC, Kabyemela E, Muehlenbachs A, et al: Plasma levels of apolipoprotein a 1 in malaria-exposed primigravidae are associated with severe anemia. PLoS One 2010;5:e8822.

20 Ray S, Renu D, Srivastava R, et al: Proteomic investigation of falciparum and vivax malaria for identification of surrogate protein markers. PLoS One 2012;7:e41751.
21 Ray S, Kamath KS, Srivastava R, et al: Serum proteome analysis of vivax malaria: an insight into the disease pathogenesis and host immune response. J Proteomics 2012;75:30633080.

22 Chukwuocha UM, Eke KN: Malaria parasite status and cholesterol level of malaria patients in parts of the Imo River Basin of Nigeria. Asian Pac J Trop Med 2011;4:993-996.

23 Agbedana EO, Salimonu LS, Taylor GO, et al: Studies of total and high density lipoprotein cholesterol in childhood malaria: a preliminary study. Ann Trop Med Parasitol 1990;84: 529-530.

24 WHO: Basic malaria microscopy, 2010. http:// whqlibdoc.who.int/publications/2010/ 9789241547826_eng.pdf.

25 Friedewald WT, Levy RI, Fredrickson DS: Estimation of the concentration of low-density lipoprotein cholesterol in plasma, without use of the preparative ultracentrifuge. Clin Chem 1972;18:499-502.

26 Bansal D, Bhatti HS, Sehgal R: Altered lipid parameters in patients infected with Entamoeba histolytica, Entamoeba dispar and Giardia lamblia. Br J Biomed Sci 2005;62:6365.

27 Ben Mamoun C, Prigge ST, Vial H: Targeting the lipid metabolic pathways for the treatment of malaria. Drug Dev Res 2010;71:4455.

28 Peters W: Adaptation of the malaria parasite to its environment during the life cycle. J Parasitol 1971;57:120-125. 